judicious employment of the new method never produces serious accidents; that the method sometimes fails on account of some lesion of the heart vessels or nerves; but that in simple sea-sickness it always produces amelioration, aud generally a prompt cure of this affection.

\section{REPORT OF A CASE OF CEREBRAL CYST. RECOVERY.}

Read in the Sedtion on Surgery and Anatomy, at the Thirty-ninth Annual Meeting of the American Medical A ssociation, May, 1888.

BY J. F. PEYTON, M.D.,

OF STANFORD, KY.

Common experience, as well as the literature of surgery, teaches that wounds involving the brain heal readily when secondary inflammation does not take place, and because of the risk in this direction a prognosis must always be unfavorable, though many cases are on record after wound of this organ in which there was full recovery.

From punctured fractures of the skull involving the dura mater there is equal danger, because the dura is very sensitive and the projecting spiculæ irritate the brain at its every pulsation, and from this source there is inflammation of the meninges and death as a consequence. The surgeon usually makes as early efforts as possible for the removal of this foreign body, knowing the longer it remains the greater is the danger from the inflammation spreading along the cellular tissue which surrounds the branches of the meningeal arteries, and by this means reaching the base of the skull.

When meningitis ensues from a traumatism, with suppuration as a result, the hope of the patient is by letting out the imprisoned matter; and where those rare pathological entities, cysts, communicate with the cranial cavity, the operation of trephining is imperatively demanded, as in the case operated on by myself, and which, with your permission, I will briefly report.

John Proctor, of Mt. Vernon, Ky., æet. 22, received a blow upon the left side of the head in 1880 , which produced a punctured fracuture of the parietal bone-unconsciousness quickly ensued. Elevation of the depressed bone, by Drs. Brown and McKee, of that place, was next undertaken, for prudential reasons, till the end of the third day. This event was not followed by anything unusual, and after the lapse of eight more days the mind became clear and he progressed to apparent recovery without an untoward symptom. Three years passed, when he was seized with an epileptic convulsion, the seizures alternating as to frequency and severity. His attending physician desiring a consultation, I was called about the middle of October, I884. We agreed as to depressed bone, the depression being one inch posterior to the coronal suture and the same distance from the mesial line in the temporal bone on the left side. Trephining was at once done. The button removed was three-fourths of an inch in diameter, and from the center of this there projected a spicula one-fourth of an inch in length, and sharp, from the inner table. The brain tissues were firmly attached around the base and the anterior portion of this spicula, and with difficulty it was detached by the handle of the scalpel.

The appearance of the underlying tissues was granular, or cell-like, and highly vascular. The wound was dressed in the usual way, there was no recurring inflammatory symptoms and in a few days it was healed. He had no convulsion for six weeks, but at the beginning of the seventh he played a game of base-ball, the fit occurring on the grounds.

The convulsions having got a start, took place with regularity up to the time of the last operation (of which I will now speak), Feb. I I, I 888. Right well nourished and his functions generally in good shape, in consultation with Dr. A. W. Johnstone, of Danville, Ky., we concluded to do another trephining, and the second button was removed. An incision was made through the dura and the pia mater, when there was revealed a cyst as large as a guinea egg, and whose walls were almost transparent, with a congerie of small vessels traversing it in divers directions. By hooking the cyst with a tenaculum and making an incision through the cyst wall, a half-ounce of clear fluid escaped, the last to come being tinged with blood. The skin flap was in the shape of a horse-shoe, in consequence of the scars or cicatrices made by previous operations. Three drainage tubes were placed in the wound, an opening made in the center, immediately over the incision of cyst, and one tube included in the button-hole, but not extending through the membranes, nor into the cyst, by which device direct drainage was made. The other two tubes were passed through the same opening and were brought out at the upper and lower angles of the flap wound. There were no antiseptic solutions or precautions employed in the treatment of the case. Cleanliness and pure water were our weapons, and he got along beautifully till the close of the thirdiday, at which time he had a fever of $105^{\circ} \mathrm{F}$., his pulse was I4O, respiration 45 , the right arm paralyzed, and a stupor amounting almost to coma, which made the prognosis doubtful. The flap was at once reopened, the wound thoroughly douched in cold water, the drainage tubes well washed and replaced, and without further medication, in six hours the temperature fell to $100^{\circ} \mathrm{F}$., the breathing became normal, the pulse 90 per minute, the mind clear, a desire for food, and the danger was passed. From the angles of the wound the tubes were removed on the fourth day, but the direct tube remained in its place till the evening of the eighth, at which time it was removed, though the discharge continued, more or less profuse, for 
about three weeks. The result so far has been all that we could wish or hope for. He has had but one slight convulsion since the operation, which was on the night following this event. The mind and memory seem intact, his health is good, and at present he is following his daily vocation.

\section{MEDICAL PROGRESS.}

Hydatid Cyst of the ORBi's.-At the Ophthalmological Society of London, December I3, I 888, Dr. RockLIFFE brought forward a case of suppurating hydatid cyst of the orbit. The patient, a laborer aged 33, had first noticed an affection of the sight of the left eye in I882. He had several attacks of inflammation in it, and the vision gradually deteriorated till, in April, r887, he was quite blind with it. There was then marked protrusion, some ptosis, and the action of all the ocular muscles, except the external rectus, was very limited. Nothing definite was made out as to the condition of the orbit. Eighteen months later, having had more attacks of pain, the patient consented to an operation. An exploratory puncture with a scalpel having given no results, the orbit was more freely opened up and, the eye being removed, a suppurating hydatid cyst was found at the apex of the orbit. The rarity of the affection and the difficulties of diagnosis were briefly alluded to. MR. BRAILEY asked if there were hydatids in other parts of the body. In one case he had seen it would have been impossible to have made the diagnosis if the bosses caused by the development of hepatic hydatids could not have been felt. He thought that in Dr. Rock-liffe's case the hydatid had developed in the substance of one of the ocular muscles. MR. HULKE had only seen three or four cases, and he thought an absolutely certain diagnosis could not be made. In one of these cases there had been suppuration. He did not see how suppuration could be caused by rupture of a daughter cyst. DR. ROCKLIFFE, in reply, said that the patient attributed the suppuration to a blow with a piece of iron. No hydatids could be found elsewhere. He thought it had developed behind the eye, and not attached to the muscles, for the patient had free movement in every direction.-Lancet, December 29, I888.

HYGIENE OF THE EYES.-Dr, LINCOLN, of Boston, in The Annals of Hygiene, formulates the following rules to be observed in the care of the eyes for school work:

I. A comfortable temperature, and especially let the feet be warm and dry.

2. Good ventilation.

3. Clothing at the neck loose ; the same as regards the rest of the body.

4. Posture erect; never read lying down or tooping.
5. Little study before breakfast or directly after a hearty meal; none at all at twilight or late at night.

6. Great caution about study after recovery from fevers.

7. Light abundant, but not dazzling.

8. Sun not shining on desk or on objects in front of the scholar.

9. Light coming from the left hand, or left and rear, under some circumstances from in front.

10. The book held at right angles to the line of sight, or nearly so.

I I. Frequently rest by looking up.

I 2. Distance of book from eye about fifteen inches.

UMBILICAL HEMORRHAGE IN THE NEWBORN. -DR. OTto Trass has reported a case, with some general remarks on the condition which produces it, in the Berliner Klinische Wochenschrift. Dr. Trass divides the cases into either spontaneous or traumatic; those produced by rupture of the cord, etc. In the latter case the hemorrhage easily ceases by the application of persulphate of iron and firm compression, but it is far otherwise with the cases of spontaneous umbilical hemorrhage. This affection is usually fatal with the newborn. From its analogy to scurvy and hemophilia he proposes the term "omphalorrhagia of the newborn." Out of 336 cases which Dr. Trass has found of record, there were only 3 where the hemorrhage spontaneously ceased, and the recoveries were only 32 per cent. That is to say, more than two-thirds of the cases have proved fatal.

Dr. Trass has concluded that the best means of treatment of these cases is to pass a threaded needle through the skin around the whole umbilicus and ligate it in mass.

A NEW USE FOR ETHER DURING ANASTHhSIA.-DR, H, A. HARE (University Medical Magazine, November, I888), calls attention to the fact that very frequently during the early stages of the administration of an anæsthetic the patient "forgets to breathe," even before the ability to perceive peripheral irritation is lost. Even later in anæsthesia, when the breathing suddenly ceases, we are accustomed to use cold water externally and to slap the patient with wet towels. Such measures are generally called for hurriedly, and it is not at all uncommon for an exasperating delay to occur before the water arrives. The ether is always at hand, however, and I have found that in a large number of instances, both in man and in the lower animals, the free use of ether poured upon the belly causes so great a shock by the cold produced by its evaporation as to cause a very deep inspiration, which is often followed by the normal respiratory movements. This is, of course, a simple procedure, and one which has probably been used by others, but I have never seen it so employed.-Coll. and Clin. Record. 